\title{
Effects of Microstructure of Deposited Sn Films and Orientation Index of Cu Foils on Sn Whisker Formation Using Substitutionally-Deposited Sn Films*1
}

\author{
Naoki Okamoto ${ }^{1}$, Yuko Fujii ${ }^{1, * 2}$, Hiroaki Kurihara ${ }^{2}$ and Kazuo Kondo ${ }^{1}$ \\ ${ }^{1}$ Department of Chemical Engineering, Graduate School of Engineering, Osaka Prefecture University, Sakai 599-8531, Japan \\ ${ }^{2}$ Mitsui Mining and Smelting Co., Ltd., Tokyo 141-0032, Japan
}

The effects of the orientation indexes of $\mathrm{Cu}$ foils, used as a copper pattern for flexible printed circuits (FPC), and the grain size of substitutionally-deposited crystalline Sn films on Sn whisker formation were investigated. In particular, the relationship between the grain size of substitutionally-deposited Sn films and the structure of intermetallic compound deposits formed at the interface between the substitutionallydeposited $\mathrm{Sn}$ films and $\mathrm{Cu}$ foils, as a function of aging was examined. Two types of $\mathrm{Cu}$ foils were used as substrates in this study. One had granular-shaped grains $0.5 \sim 1.0 \mu \mathrm{m}$ in size while other had pillar-shaped grains about $5.0 \mu \mathrm{m}$ in size. We called the former "with the gelatin additive" and the latter "with the $\mathrm{Cl}^{-}$ion additive" since we used gelatin and $\mathrm{Cl}^{-}$ions for the fabrication of $\mathrm{Cu}$ foils. In addition, single crystal $\mathrm{Cu}$ (100), (110), (111) samples were also used as substrates. Two types of the Sn deposition bath were used in this study, a hydrofluoroboric acid bath and an organic acid bath. The structures of the deposited Sn films and Cu foils were investigated using TEM and SEM. The number of whiskers formed on the Sn-deposited film increased with aging. The number of whiskers formed on the substitutionally-deposited Sn films using the hydrofluoroboric acid bath was larger than that formed using the organic acid bath. The number of whiskers formed on the deposited Sn films on the $\mathrm{Cu}$ single crystal (111) was larger than that formed on the deposited Sn films on the other single crystals. The mechanism of inhibiting whisker formation by heat treatment was also investigated. No whiskers were seen on the substitutionally-deposited Sn films with heat treatment. Analysis of TEM selected-area diffraction patterns obtained from the sample subjected to heat treatment indicated the presence of $\mathrm{Cu}_{6} \mathrm{Sn}_{5}$ and $\mathrm{Cu}_{3} \mathrm{Sn}$ intermetallic compound deposits near the interface between the deposited $\mathrm{Sn}$ films and the Cu foils. The results suggest that the microstructures of the substrates strongly affect the Sn whisker formation on substitutionally-deposited Sn films.

[doi:10.2320/matertrans.M2009249]

(Received July 16, 2009; Accepted September 3, 2009; Published October 25, 2009)

Keywords: whiskers, tin, copper, electroless deposition, intermetallic compound

\section{Introduction}

Sn whiskers are formed in abnormally deposited films. They are well known as the cause of short circuits in various electronic devices. ${ }^{1)}$ It is well known from previous research that whisker formation can be inhibited by the addition of $\mathrm{Pb}$ into the deposited Sn film. ${ }^{1)}$ However, the addition of $\mathrm{Pb}$ cannot be routinely used for inhibiting whisker formation due to environmental problems and concerns, and related regulations. ${ }^{1)}$ It is thus necessary to develop new alternate methods for inhibiting whisker formation. ${ }^{2)}$

A number of studies have been previously conducted for elucidating the structure and the growth mechanism of $\mathrm{Sn}$ whiskers. Most of these studies have investigated the relationship between whisker growth and microstructures of the Sn films, ${ }^{2-5)}$ and possible causes of whisker formation have been discussed. In general, intermetallic compounds within the Sn deposits, internal stresses, and crystal coherency between the deposited Sn film and substrate are known to be key causes of whisker formation ${ }^{2-5)}$ and these continue to be investigated. ${ }^{6}$ Heat treatments have been explored for inhibiting whisker formation. However, the mechanisms of heat treatments for inhibiting whisker formation are still unknown. There have been very few studies on the $\mathrm{Sn}$ whiskers formed on substitutionally-deposited Sn films. From practical considerations, substitutional deposition is

\footnotetext{
${ }^{* 1}$ This Paper was Originally Published in Japanese in J. Japan Inst. Metals 73 (2009) 116-123.

${ }^{* 2}$ Graduate Student, Osaka Prefecture University
}

better suited for electronic device interconnection applications, since the presence of a seed layer to conduct electricity is not necessary.

We have previously reported the effects of surface morphologies and grain sizes of substrates on whisker formation using substitutionally-deposited Sn films. ${ }^{7)}$ In the present study, the effects of orientation indices of $\mathrm{Cu}$ foil substrates and grain size of the substitutionally-deposited Sn films on Sn whisker formation were investigated. In general, the structures of the Sn whiskers and deposited Sn films are strongly affected by the deposition bath composition and other deposition conditions. ${ }^{1,4)}$ However, for the substitutional deposition, it is assumed that while the same bath compositions and conditions were used for deposition, the microstructures of the deposited Sn films were changed by the microstructure of the substrate, including the grain size and surface morphology. This is because, by using the substitutional deposition, the rate of deposited film growth depends on the dissolution rate of the substrate. In addition, the dissolution rate of the substrate mainly depends on the structure of the substrate, such as grain size, orientation relationship and segregation of impurities. Therefore, several types of single crystal $\mathrm{Cu}$ substrates were used in this study. In addition, we investigated the effects of heat treatment for inhibiting whisker formation.

\section{Experimental Method}

Two types of $\mathrm{Cu}$ foils were used as substrates. For the first type, galvanostatic electrodeposition with a current 

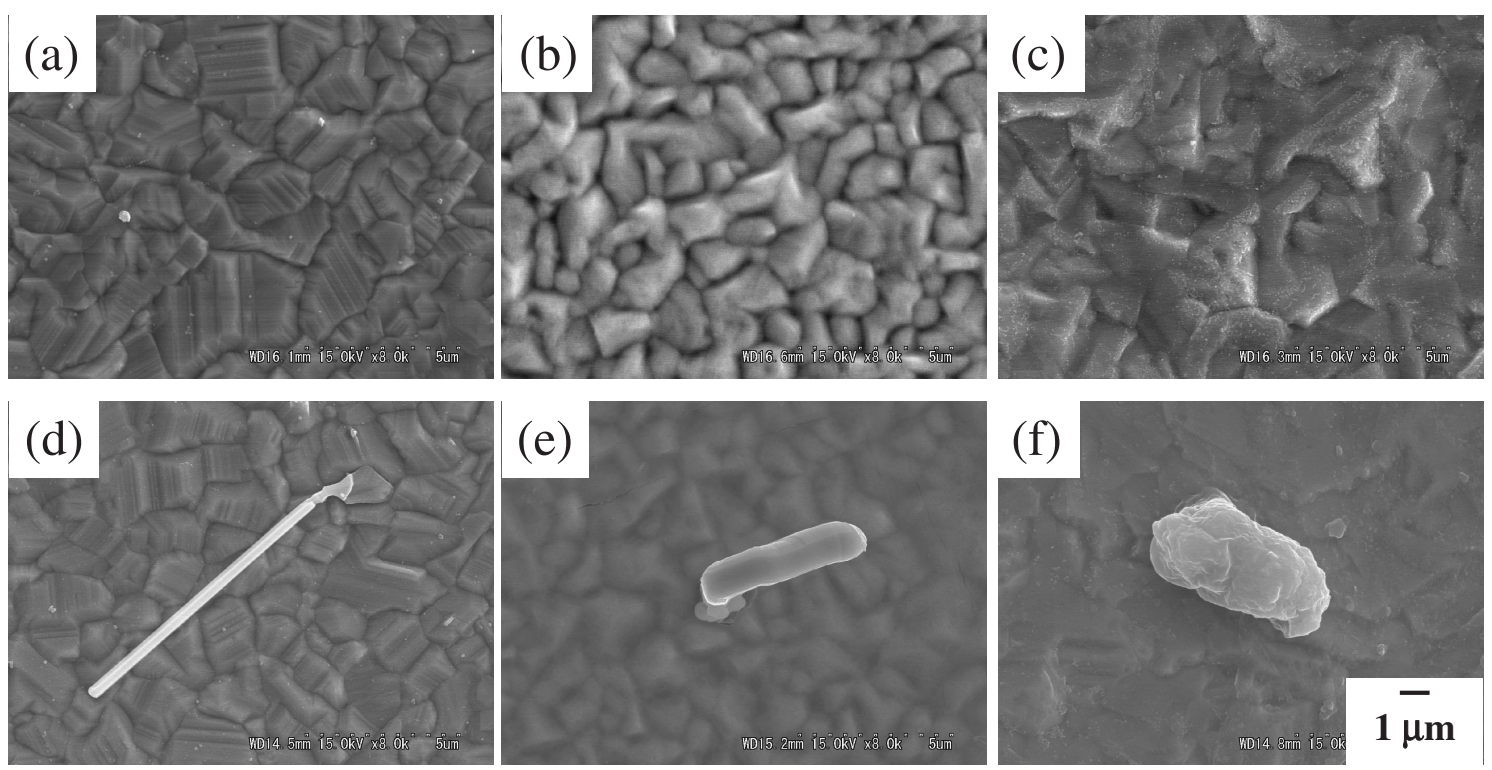

Fig. 1 Surface morphologies of deposited Sn films (organic acid bath) formed on Cu substrates (single crystal). (a) As-deposited on Cu (100), (b) as-deposited on $\mathrm{Cu}$ (110), (c) as-deposited on $\mathrm{Cu}$ (111), (d) kept for 1.3 Ms under ambient conditions after deposition on Cu (100), (e) kept for 1.3 Ms under ambient conditions after deposition on $\mathrm{Cu}$ (110), (f) kept for $1.3 \mathrm{Ms}$ under ambient conditions after deposition on $\mathrm{Cu}(111)$.

density of $125 \mathrm{~A} \cdot \mathrm{m}^{-2}$ was used and the film thickness of the $\mathrm{Cu}$ foil was adjusted to $25 \pm 2 \mu \mathrm{m}$ by controlling the deposition time. Galvanostatic electrolysis was carried out while the bath was stirred. The anode and cathode were placed in parallel and the distance between the anode and cathode was $10 \mathrm{~mm}$. The Ti board (the thickness of $0.5 \mathrm{~mm}$, $99.5 \%$ ), which is covered by insulation tape except the electrode area of $2 \times 2 \mathrm{~cm}^{2}$ for $\mathrm{Cu}$ deposition, was used for the cathode. Two types of $\mathrm{Cu}$ deposition baths were used for the $\mathrm{Cu}$ deposition. The $\mathrm{Cu}$ deposition bath consisted of $24 \mathrm{~kg} \cdot \mathrm{m}^{-3} \mathrm{CuSO}_{4} \cdot 5 \mathrm{H}_{2} \mathrm{O}, 10 \mathrm{~kg} \cdot \mathrm{m}^{-3} \mathrm{H}_{2} \mathrm{SO}_{4}$ with the addition of either $50 \mathrm{~g} \cdot \mathrm{m}^{-3}$ gelatin or $50 \mathrm{~g} \cdot \mathrm{m}^{-3} \mathrm{Cl}^{-}$ion. In this study, we have termed the $\mathrm{Cu}$ foils made using the gelatin additive bath "with the gelatin additive". We call the $\mathrm{Cu}$ foils made using $\mathrm{Cl}^{-}$ion additive bath "with the $\mathrm{Cl}^{-}$ion additive".

(100), (110) and (111) Cu single crystal plates $(\varphi 10 \mathrm{~mm})$ were also used as substrates. These were carefully cleaned and smoothed before use. They were first smoothed by mechanical polishing and then cleaned by electrolytic polishing using a phosphoric acid solution for removing remaining unevenness and the Beilby Layer.

The Sn films were deposited to a thickness of about $0.6 \mu \mathrm{m}$ onto the $\mathrm{Cu}$ foils using $\mathrm{Sn}$ substitutional deposition. The $\mathrm{Sn}$ electroless deposition bath consisted of $\mathrm{Sn}$ (II) complexes for metal ions, thiourea as the complexing agents and additives. When using the hydrofluoboric acid as the additive, we termed the bath the "hydrofluoboric bath". In addition, we call the deposited Sn films made using organic acid additive bath the "organic acid bath". In this study, the "organic acid bath" was used for a basic condition of Sn substitutional deposition.

The deposited Sn films were kept at room temperature and humidity. The morphologies and the number of whiskers formed on the deposited Sn film with aging were examined. Surface morphologies were observed using a scanning electron microscope (SEM) (Hitachi, S-4300). The crystallographic structures of the deposited films and substrate were investigated using a transmission electron microscope (TEM) (JEOL JEM-2010F). Elemental analysis was carried out using an EDS system (NORAN EDS UTW-type Si(Li) detector). Crystal orientations of the deposited Sn films were evaluated by X-ray diffractometry (XRD). These orientations were determined from the peak height of the intensity profile obtained by XRD $2 \theta-\theta$ scans.

\section{Results}

\subsection{Sn whiskers formed on deposited Sn films on $\mathrm{Cu}$ single crystal plates}

\subsubsection{Morphologies of the Sn whiskers and deposited Sn films}

Figure 1 shows the morphologies of the deposited Sn films formed on various $\mathrm{Cu}$ single crystal plates. In this article, we call the samples using the (100), (110) and (111) $\mathrm{Cu}$ single crystals as (100), (110) and (111), respectively. The deposited Sn film formed on (100) (a) has blocky grains which are $1 \sim 10 \mu \mathrm{m}$ in diameter. (110) (b) has triangular grains which are $1 \sim 5 \mu \mathrm{m}$ in diameter. (111) (c) has triangular pyramid shaped grains which are $1 \sim 10 \mu \mathrm{m}$ in diameter. The morphologies of the whiskers formed on each deposited Sn films after 1.3 Ms aging are shown in Fig. 1(d), (e) and (f). For (100) (d), linear needle shaped whiskers are observed, for (110) (e), curvilinear shaped whiskers are observed, and for (111) (f), nodular shaped whiskers are observed. From these results, the deposited Sn films on the three types of $\mathrm{Cu}$ single crystal plates show differences in morphology and shape of the whiskers. However, we could not determine the crystallographic coherency or the orientational relationship between the deposited $\mathrm{Sn}$ film and $\mathrm{Cu}$ single crystal plates from the results of the XRD analysis with these deposited Sn films. 


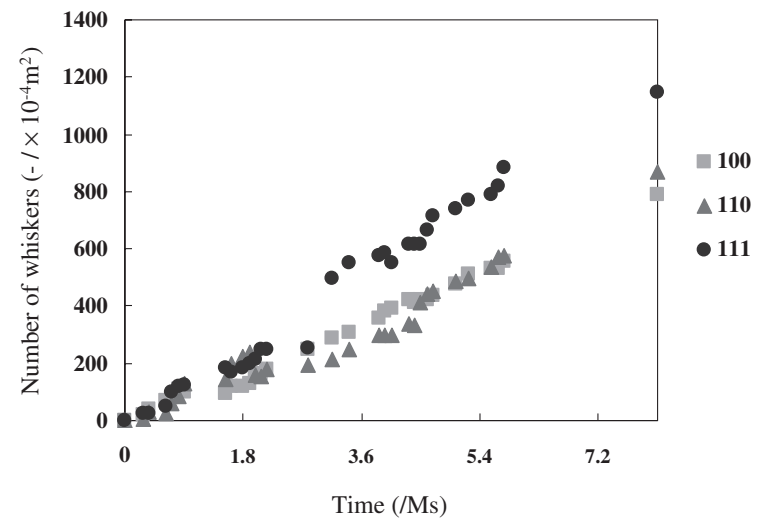

Fig. 2 Change in the number of whiskers observed on deposited Sn films (organic acid bath) on $\mathrm{Cu}$ substrate (single crystal).

The number of whiskers observed on the deposited Sn films on $\mathrm{Cu}$ single crystal plates after aging is shown in Fig. 2. This number increased linearly with increasing aging time. The number of whiskers with (111) is larger than the others. No differences were observed for the number of whiskers between (100) and (110).

\subsubsection{Cross-sectional microstructures of the deposited Sn films on $\mathrm{Cu}$ single crystal plates}

Cross-sectional TEM bright-field images of the deposited Sn films are shown in Fig. 3. All the TEM samples were fabricated using a focused ion beam (FIB) technique. The FIB fabrication was performed after forming a protective coating of $\mathrm{Pt}$ on the deposited $\mathrm{Sn}$ films by sputtering. During the FIB sample preparation, the sample is heated by the ion beam irradiation. It is possible that this could change the structure of the deposited $\mathrm{Sn}$ films and $\mathrm{Cu}$ substrates. In this study, we investigated the effect of heating on the deposited $\mathrm{Sn}$ films and $\mathrm{Cu}$ substrates by preliminary experiments. It was confirmed that the effect of changing the structure of the deposited $\mathrm{Sn}$ films and $\mathrm{Cu}$ substrates by the heating during the FIB fabrication is smaller than that by aging.

In the case of the (100) $\mathrm{Cu}$ single crystal plate (a), the grain size of the deposited $\mathrm{Sn}$ film was $200 \mathrm{~nm} \sim 2 \mu \mathrm{m}$. A layershaped structure with a thickness of $50 \mathrm{~nm}$, different from the $\mathrm{Cu}$ and the $\mathrm{Sn}$ crystals, was observed near the interface between the deposited $\mathrm{Sn}$ film and the $\mathrm{Cu}$ single crystal plate. This layer-shaped structure was determined to be the intermetallic compound $\mathrm{Cu}_{6} \mathrm{Sn}_{5}$ based on analysis of selected-area diffraction patterns. In the case of the (110) sample (b), the grain size of the deposited $\mathrm{Sn}$ film is $400 \mathrm{~nm} \sim 3 \mu \mathrm{m}$, and the intermetallic compound $\mathrm{Cu}_{6} \mathrm{Sn}_{5}$ of about $50 \mathrm{~nm}$ thickness was observed near the interface between the deposited $\mathrm{Sn}$ film and the $\mathrm{Cu}$ single crystal plate. In the case of the (111) sample (c), the grain size of the deposited Sn film was $1.5 \mu \mathrm{m} \sim 5 \mu \mathrm{m}$ and $\mathrm{Cu}_{6} \mathrm{Sn}_{5}$ with a thickness of about $100 \mathrm{~nm}$ was observed near the interface between the deposited $\mathrm{Sn}$ film and the $\mathrm{Cu}$ single crystal plate. The deposited Sn films with (111) (c) were thinner than those with (100) (a) and with (110) (b). We carried out many experiments depositing $\mathrm{Sn}$ films on the (111) $\mathrm{Cu}$ single crystal plate while changing the deposition time. However, the film thickness of $2 \mu \mathrm{m}$, shown in Fig. 3, was the largest. The thickness of the intermetallic compound $\mathrm{Cu}_{6} \mathrm{Sn}_{5}$ with (111) was thicker than that with (100) (a) or with (110) (b).

Figure 4 shows cross-sectional TEM bright and dark field images of the deposited $\mathrm{Sn}$ films and $\mathrm{Cu}$ single crystal plates after $2.6 \mathrm{Ms}$ aging. Bright-field images are shown in Fig. 4(a), (b) and (c), and dark field images are shown in Fig. 4(d), (e) and (f). The intermetallic compound $\mathrm{Cu}_{6} \mathrm{Sn}_{5}$ of about $50 \mathrm{~nm}$ thickness was observed near the interface between the deposited $\mathrm{Sn}$ films and the $\mathrm{Cu}$ single crystal plate (100) (a), (110) (b) and (111) (c). These results coincide with the contrast of the dark field images (d), (e) and (f). The intermetallic compound $\mathrm{Cu}_{6} \mathrm{Sn}_{5}$ after aging is $2 \sim 10$ times as thick as that of the as-deposited films. In addition, the thickness of the intermetallic compound $\mathrm{Cu}_{6} \mathrm{Sn}_{5}$ and deposited Sn film were not uniform.

\subsection{Sn whiskers formed on deposited Sn films with different grain sizes}

\subsubsection{Morphologies of the Sn whiskers}

The morphologies of the deposited Sn films, deposited on the two types of $\mathrm{Cu}$ foils using the two different deposition baths are shown in Fig. 5. In the case of using the hydrofluoboric bath (a), (b), the deposited Sn films have triangular pyramid-shaped deposits. For the organic acid bath case (c), (d), the deposited Sn films have round and flattened-shaped deposits. The sizes of these deposits on the deposited Sn films on $\mathrm{Cu}$ foils "with the gelatin additive" (a), (c) are smaller than those on the $\mathrm{Cu}$ foils "with the $\mathrm{Cl}^{-}$ion additive" (b), (d). From our previous study, ${ }^{7)}$ the grain size of the $\mathrm{Cu}$ foils with the gelatin additive is about $0.3 \mu \mathrm{m}$ and that with the $\mathrm{Cl}^{-}$ion additive is about $5 \mu \mathrm{m}$. The grain sizes of the deposited Sn films with the hydrofluoboric bath are (a) $70 \mathrm{~nm}$ with the gelatin and (b) $1 \mu \mathrm{m}$ with the $\mathrm{Cl}^{-}$ion additive respectively. With the organic acid bath, the grain sizes of the deposited Sn
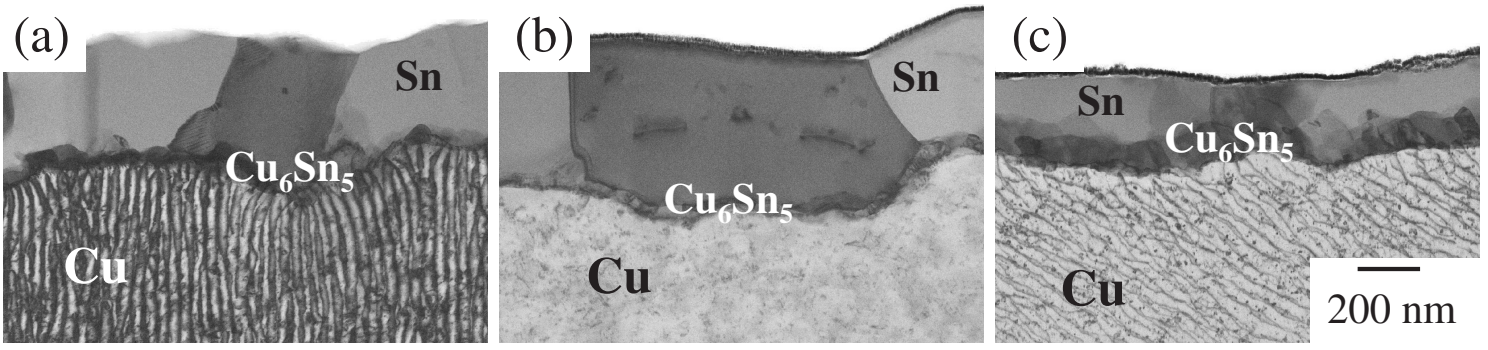

Fig. 3 Cross-sectional TEM bright-field images of as-deposited $\mathrm{Sn}$ films (organic acid bath) on $\mathrm{Cu}$ substrates (single crystal). (a) $\mathrm{Cu}$ (100), (b) $\mathrm{Cu}(110)$, (c) $\mathrm{Cu}(111)$. 

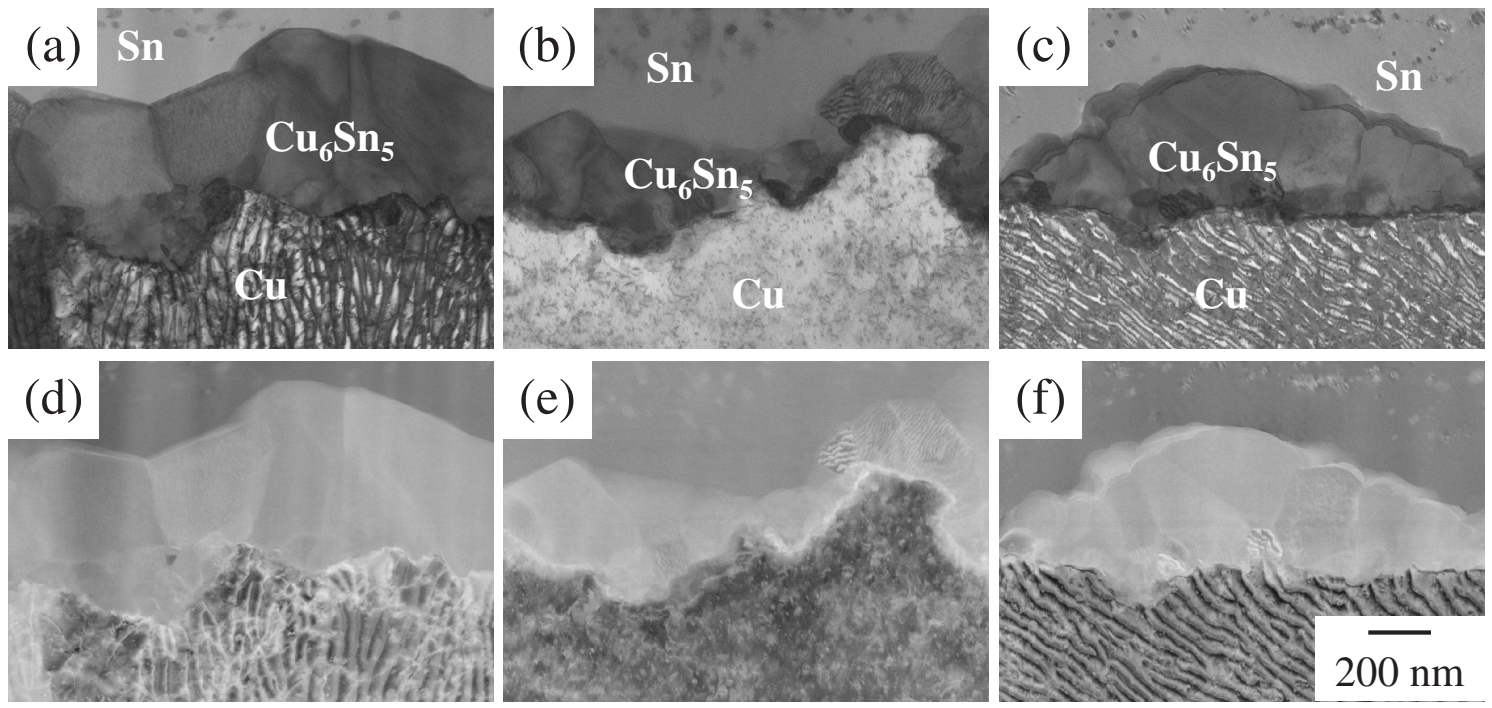

Fig. 4 Cross-sectional TEM images of the interface between Cu substrates (single crystal) and deposited Sn films (organic acid bath) kept for 2.6 Ms under ambient conditions. (a) Bright-field image of the Sn film on Cu (100), (b) BFI of Sn on Cu (110), (c) BFI of Sn on Cu (111), (d) Dark-field image of (a), (e) DFI of (b), (f) DFI of (c).
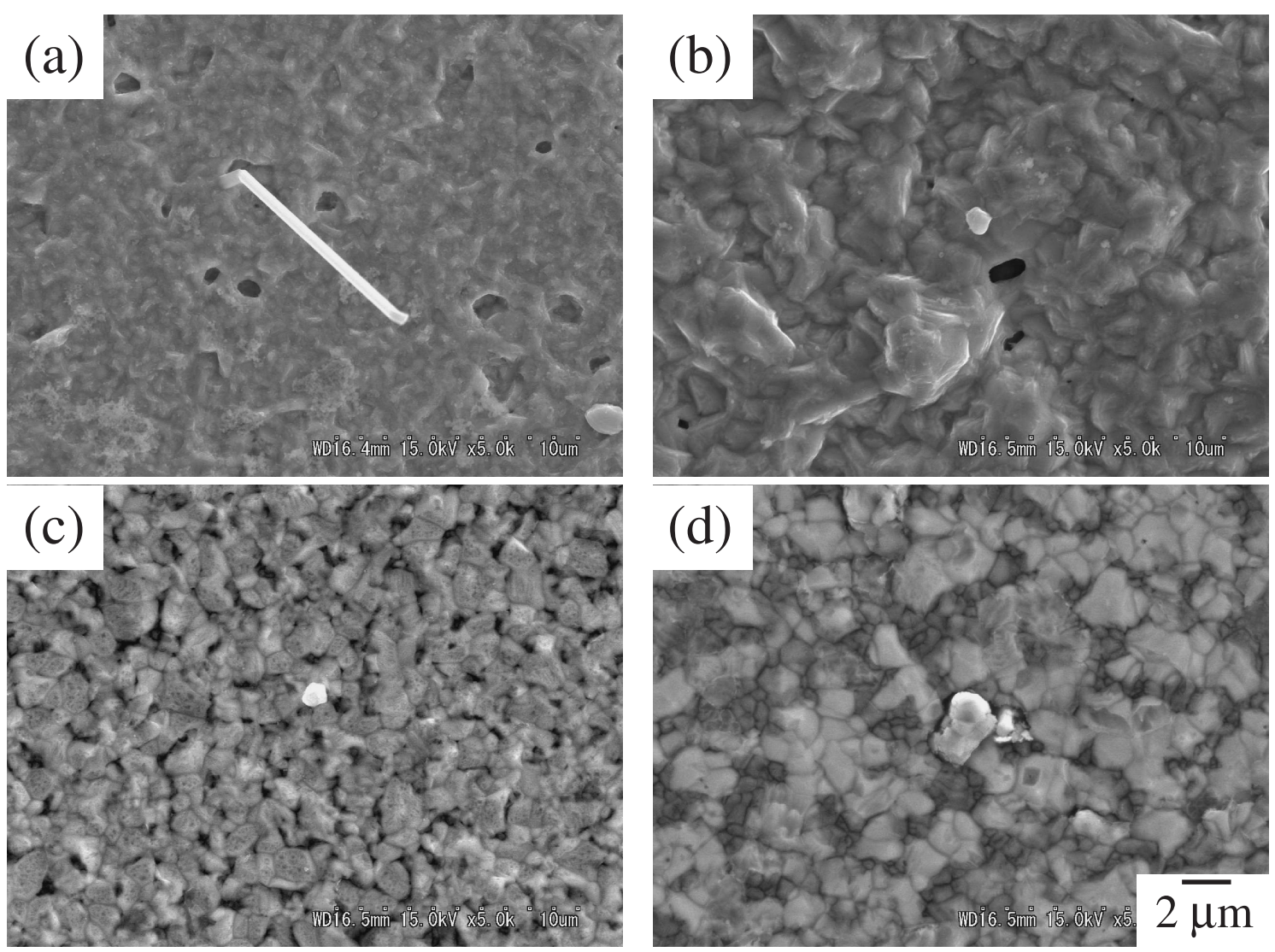

Fig. 5 Secondary electron images of the surfaces of the deposited Sn films. (a) Deposited by hydrofluoroboric acid bath on Cu foil (gelatin-added bath), (b) deposited by hydrofluoroboric acid bath on $\mathrm{Cu}$ foil $\left(\mathrm{Cl}^{-}\right.$-added bath), (c) deposited by organic acid bath on $\mathrm{Cu}$ foil (gelatin-added bath), (d) deposited by organic acid bath on $\mathrm{Cu}$ foil $\left(\mathrm{Cl}^{-}\right.$-added bath).

films are (c) $150 \mathrm{~nm}$ with the gelatin additive and (d) $2 \mu \mathrm{m}$ with the $\mathrm{Cl}^{-}$ion additive.

Figure 6 shows the number of whiskers formed on each type of the deposited Sn films as a function of the aging time. The number of whiskers increased with aging time. There are differences in the number of whiskers for the hydrofluoboric acid bath case $(\bigcirc, \square)$ and the organic acid bath case $(\bullet, \square)$.
The number of whiskers was found to be the largest for the hydrofluoboric acid bath and the gelatin additive case.

\subsubsection{Cross-sectional structures of the Sn whiskers}

Figure 7 shows cross-sectional TEM bright-field images of the deposited Sn films near the interface between the Sn film and the $\mathrm{Cu}$ foil after $2.6 \mathrm{Ms}$ aging. The grain sizes of the deposited $\mathrm{Sn}$ films were $350 \mathrm{~nm}$ with the hydrofluoboric acid 


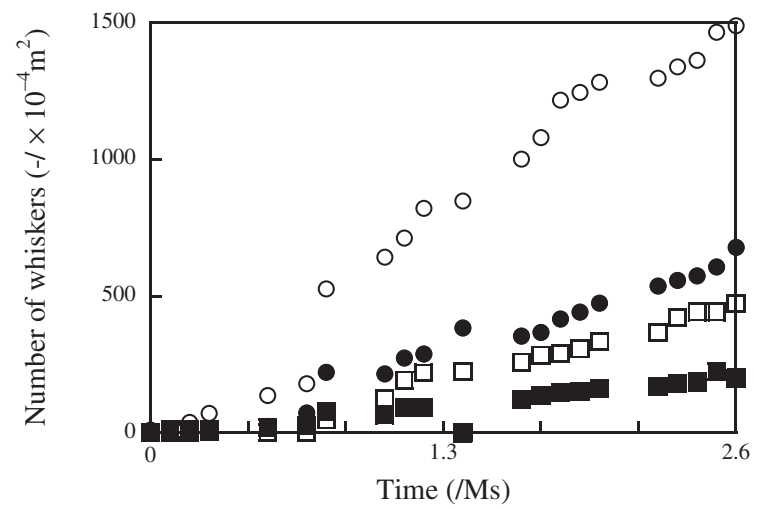

Fig. 6 Change in the number of whiskers observed on the deposited $\mathrm{Sn}$ films (organic acid bath) on $\mathrm{Cu}$ foils. $\bigcirc \mathrm{Sn}$ film, which was deposited by using hydrofluoroboric acid bath, on $\mathrm{Cu}$ foil with a gelatin additive. $\square \mathrm{Sn}$ film, which was deposited by using hydrofluoroboric acid bath, on $\mathrm{Cu}$ foil with a Cl- ions additive. Sn film, which was deposited by using organic acid bath, on $\mathrm{Cu}$ foil with a gelatin additive. Sn film, which was deposited by using organic acid bath, on $\mathrm{Cu}$ foil with a $\mathrm{Cl}$ - ions additive.

bath and the gelatin additive (a), $1 \mu \mathrm{m}$ with the hydrofluoboric acid bath and the $\mathrm{Cl}^{-}$ion additive (b), $700 \mathrm{~nm}$ with organic acid bath and the gelatin additive (c) and $2 \mu \mathrm{m}$ with organic acid bath and the $\mathrm{Cl}^{-}$ion additive (d). These grain sizes are similar to that of the as-deposited $\mathrm{Sn}$ films. However, the nodular shaped structures, different from the $\mathrm{Cu}$ and the Sn structures and not seen in the as-deposited
Sn films, were observed near the interface between the deposited $\mathrm{Sn}$ film and the $\mathrm{Cu}$ foil. These nodular shaped structures were determined to be the intermetallic compound $\mathrm{Cu}_{6} \mathrm{Sn}_{5}$ based on analysis of the selected-area diffraction patterns.

For the deposited Sn film with the gelatin additive (a), (c), voids (indicated by white arrows in Fig. 7(a) and (c)) with $10 \sim 100 \mathrm{~nm}$ diameter were observed near the interface between the $\mathrm{Sn}$ film and $\mathrm{Cu}$ foil. With the $\mathrm{Cl}^{-}$ion additive (b), (d), layer-shaped $\mathrm{Cu}_{6} \mathrm{Sn}_{5}$ was observed near the interface between the $\mathrm{Sn}$ film and $\mathrm{Cu}$ foil. However, no voids were observed in this case either near the $\mathrm{Sn}$ film and $\mathrm{Cu}$ foil interface or in the deposited Sn film. $\mathrm{Cu}_{6} \mathrm{Sn}_{5}$ was observed on all deposited Sn films. However, the voids and nodular shaped intermetallic compound were only observed in the sample with the gelatin additive.

\subsection{Effects of heat treatment \\ 3.3.1 Number of whiskers}

The effects of heat treatment on whisker formation were investigated. The hydrofluoboric acid bath was used for $\mathrm{Sn}$ electroless deposition since the deposited Sn films formed using the hydrofluoboric acid bath had the largest number of nodules, as mentioned in section 3.2. The heat treatments were carried out in vacuo $\left(1.0 \times 10^{-2} \mathrm{~Pa}\right)$ at $400 \mathrm{~K}$ for $3.6 \mathrm{Ks}$. The heat treatment was carried out as soon as possible after the $\mathrm{Sn}$ deposition. There was no whisker formation under all conditions even after $3.6 \mathrm{Ms}$ aging.
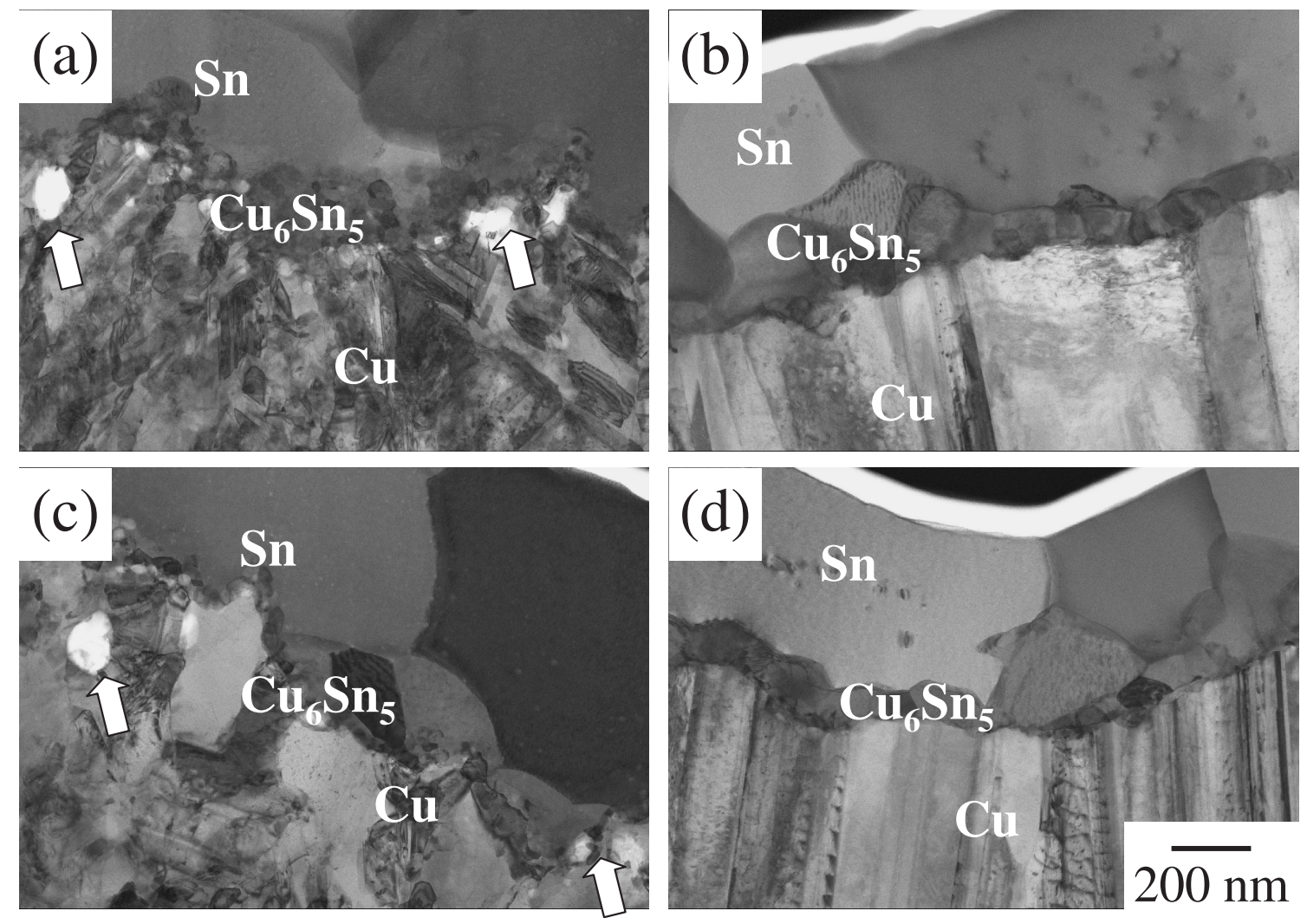

Fig. 7 Cross-sectional TEM bright-field images of the interface between $\mathrm{Cu}$ foils and deposited Sn films kept for $2.6 \mathrm{Ms}$ under ambient conditions. (a) Deposited by hydrofluoroboric acid bath on $\mathrm{Cu}$ foil (gelatin-added bath), (b) deposited by hydrofluoroboric acid bath on $\mathrm{Cu}$ foil $\left(\mathrm{Cl}^{-}\right.$-added bath), (c) deposited by organic acid bath on $\mathrm{Cu}$ foil (gelatin-added bath), (d) deposited by organic acid bath on $\mathrm{Cu}$ foil $\left(\mathrm{Cl}^{-}\right.$-added bath). 


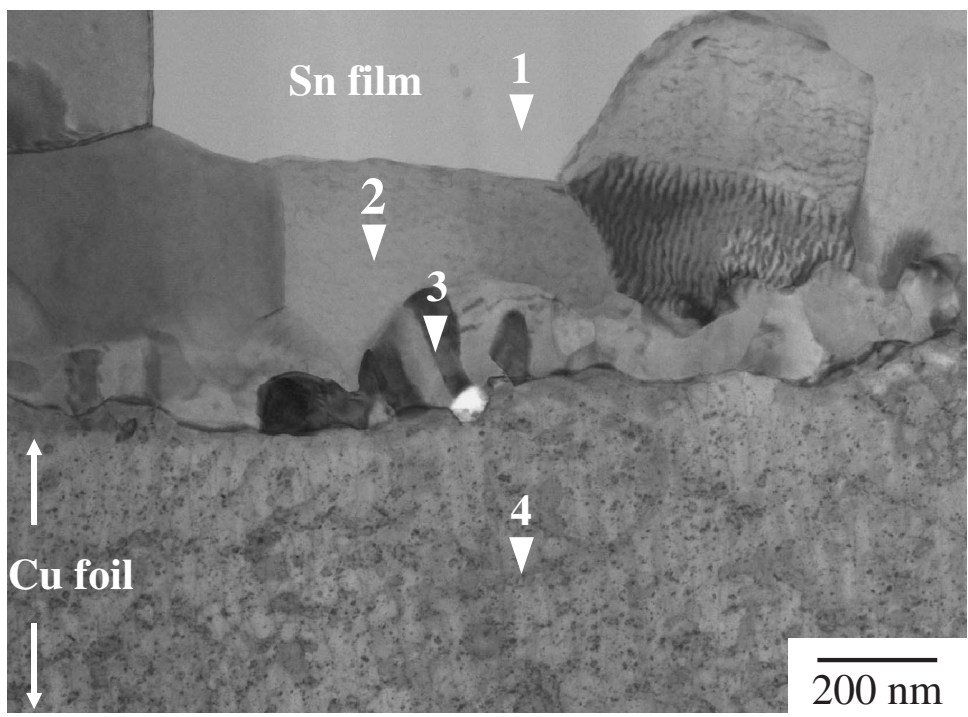

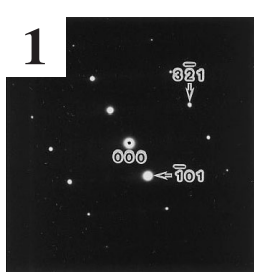

$\mathrm{Sn}$

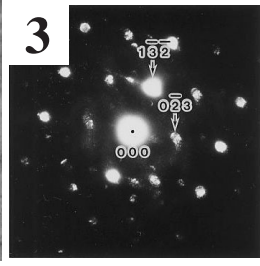

$\mathrm{Cu}_{3} \mathrm{Sn}$

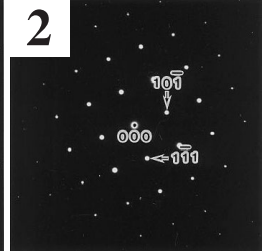

$\mathrm{Cu}_{6} \mathrm{Sn}_{5}$

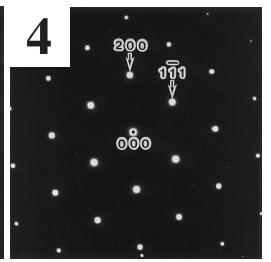

$\mathrm{Cu}$

Fig. 8 Cross-sectional TEM bright-field image and selected-area diffraction patterns of Sn film (deposited by hydrofluoroboric acid bath) and $\mathrm{Cu}$ foil (gelatin-added bath) kept for $2.6 \mathrm{Ms}$ under ambient conditions after heat treatment of $400 \mathrm{~K}-3.6 \mathrm{ks}$.

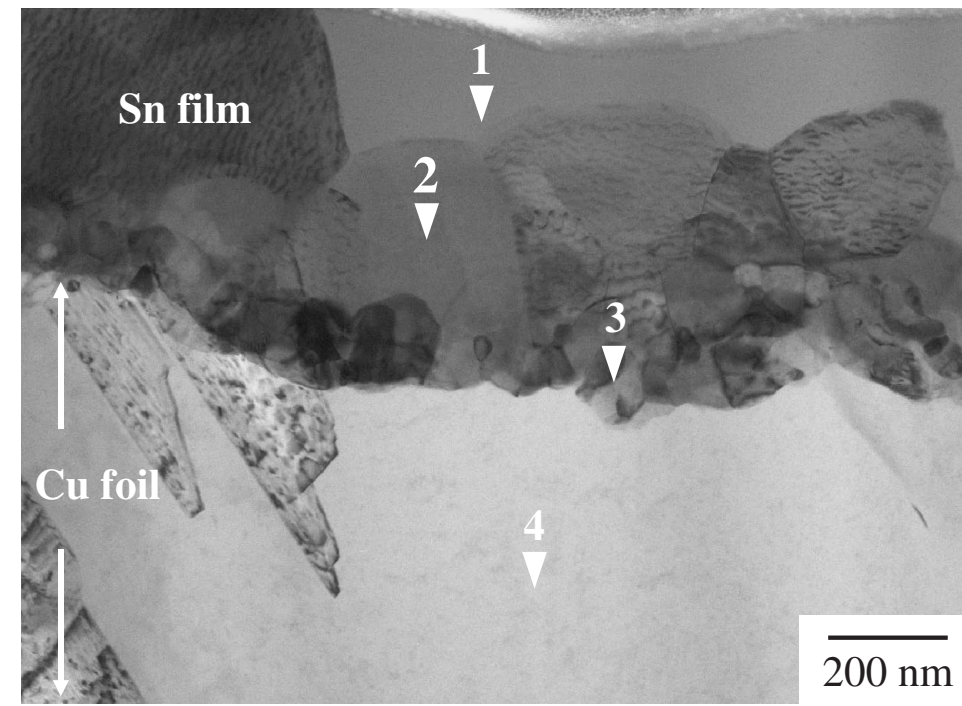

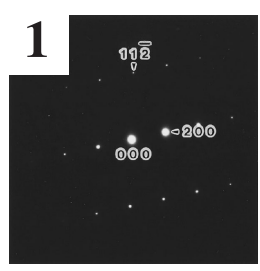

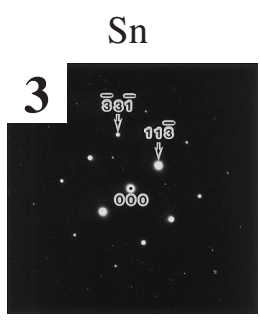

$\mathrm{Cu}_{3} \mathrm{Sn}$

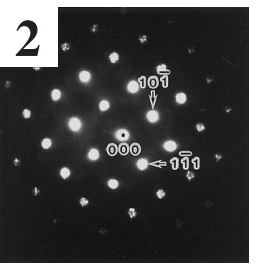

$\mathrm{Cu}_{6} \mathrm{Sn}_{5}$

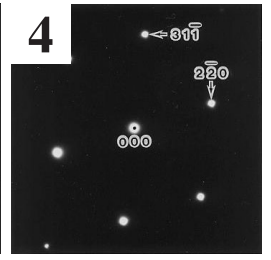

$\mathrm{Cu}$

Fig. 9 Cross-sectional TEM bright-field image and selected-area diffraction patterns of Sn film (deposited by hydrofluoroboric acid bath) and $\mathrm{Cu}$ foil $\left(\mathrm{Cl}^{-}\right.$-added bath) kept for 2.6 Ms under ambient conditions after heat treatment of $400 \mathrm{~K}-3.6 \mathrm{ks}$.

\subsubsection{Cross-sectional microstructures of deposited Sn films}

Figure 8 shows a cross-sectional TEM bright-field image and selected-area diffraction patterns near the interface between the deposited $\mathrm{Sn}$ film and $\mathrm{Cu}$ foil with the gelatin additive after $2.6 \mathrm{Ms}$ aging. The selected-area diffraction pattern numbers correspond to the numbers indicated in the bright-field image. Two types of granular shaped intermetallic compound layers were observed near the interface between the deposited $\mathrm{Sn}$ film and $\mathrm{Cu}$ foil. The first was over $200 \mathrm{~nm}$ in diameter next to the deposited Sn film. The other was under $200 \mathrm{~nm}$ in diameter next to the $\mathrm{Cu}$ foil. The first was determined to be $\mathrm{Cu}_{6} \mathrm{Sn}_{5}$ (white triangle 2) and the other was determined to be $\mathrm{Cu}_{3} \mathrm{Sn}$ (white triangle 3) based on analysis of the selected-area diffraction patterns.

The intermetallic compounds $\mathrm{Cu}_{6} \mathrm{Sn}_{5}$ (white triangle 2) and $\mathrm{Cu}_{3} \mathrm{Sn}$ (white triangle 3) were also observed near the interface between the deposited $\mathrm{Sn}$ film and $\mathrm{Cu}$ foil with the $\mathrm{Cl}^{-}$ion (Fig. 9). $\mathrm{Cu}_{6} \mathrm{Sn}_{5}$ was ordinarily observed in the deposited Sn films after aging, with or without the heat treatment. However, $\mathrm{Cu}_{3} \mathrm{Sn}$ was not observed in the deposited Sn films without heat treatment. These results suggest that $\mathrm{Cu}_{3} \mathrm{Sn}$ appeared during the heat treatment. The structures of these intermetallic compounds in the deposited Sn films were not changed by aging. No crystallographic coherency was observed between the $\mathrm{Cu}$ foils and intermetallic compound layers, from analysis of selected-area diffraction patterns. Furthermore, no grain boundaries, voids or dislocations were observed in the deposited Sn films and $\mathrm{Cu}$ foils (Fig. 8 and 9).

In order to understand the effects of impurities on intermetallic compounds and whisker formation, elemental analysis was performed. The distributions of $\mathrm{C}, \mathrm{S}, \mathrm{Cl}, \mathrm{Sn}$ and $\mathrm{Cu}$ were also analyzed using an EDS-equipped TEM. However, there was no segregation of these elements to grain boundaries or to any part of the deposited Sn films. 


\section{Discussion}

The number of whiskers, the structures of the deposited Sn films and the intermetallic compounds were changed depending on the grain size of the $\mathrm{Cu}$ foil used, ${ }^{7}$ the grain size of the deposited Sn film and the heat treatment.

In the case of using the single crystal $\mathrm{Cu}$ plates as substrates (Fig. 2), the number of whiskers formed on the deposited (111) Sn films was the largest. The thickness of the deposited (111) Sn film was smaller than that of (100) and (110). In general, the strain energy of the deposited Sn film increased with increasing thickness of the intermetallic compound $\mathrm{Cu}_{6} \mathrm{Sn}_{5} .^{2-5)}$ These results suggest that the strain energy of the deposited Sn films with (111) is larger than that of the (100) and (110) films. This large strain energy in the deposited Sn films resulted in the formation of a large number of whisker on the deposited (111) Sn film.

In the case of using $\mathrm{Sn}$ electrodeposition, $\mathrm{Cu}_{6} \mathrm{Sn}_{5}$ was usually observed in the Sn film after aging. However, in case of $\mathrm{Sn}$ electroless deposition on $\mathrm{Cu}$ single crystal plates, $\mathrm{Cu}_{6} \mathrm{Sn}_{5}$ was also observed in the as-deposited $\mathrm{Sn}$ film without aging. The reason for this is that $\mathrm{Cu}_{6} \mathrm{Sn}_{5}$ was likely formed by chemical reaction during the $\mathrm{Sn}$ substitutional deposition since a substitutional reaction is considered to form the intermetallic compound by chemical reaction. ${ }^{7)}$

A substitutional reaction only uses surface chemical reactions for deposition. The rate and process of the surface chemical reactions vary with surface energy and surface morphology of the substrate. The surface energy of $\mathrm{Cu}$ (111) is smaller than that of other $\mathrm{Cu}$ crystal orientations. ${ }^{8)}$ In addition, the deposition rate with the deposited Sn film with (111) was slower than that with (100) and (110), because the dissolution rate of $\mathrm{Cu}$ on (111), which is a close-packed structure, is slower than that on (100) and (111). Therefore, the thickness of the deposited $\mathrm{Sn}$ film and $\mathrm{Cu}_{6} \mathrm{Sn}_{5}$ formed on the (111) $\mathrm{Cu}$ single crystal plate was different from that of the other cases.

When the hydrofluoboric bath was used for the deposition, the grain sizes of the deposited Sn films were smaller than for the organic acid bath, and the number of whiskers for the hydrofluoboric bath was larger than that obtained with the organic acid bath. These results suggest that the number of whiskers depends on the grain size of the deposited Sn films.

A number of voids, seen in Fig. 7(a) and (b), are near the interface between the deposited $\mathrm{Sn}$ films and $\mathrm{Cu}$ foils and no voids were observed in the as-deposited Sn film. From these results, we conclude that the voids are Kirkendall voids. Several voids were observed in the samples with the gelatin additive compared to the samples with the $\mathrm{Cl}^{-}$ion additive. The grain size of the deposited $\mathrm{Sn}$ film with the gelatin additive was smaller than that with the $\mathrm{Cl}^{-}$ion additive. In general, the smaller the grain, the faster is the diffusion rate, since diffusion at room temperature ordinarily occurs via grain boundary diffusion. Therefore, thicker $\mathrm{Cu}_{6} \mathrm{Sn}_{5}$ formed in the sample with the gelatin additive by the diffusion of $\mathrm{Cu}$ into $\mathrm{Sn}$.

When heat treatment was used, there was no whisker formation on the deposited $\mathrm{Sn}$ films, and $\mathrm{Cu}_{6} \mathrm{Sn}_{5}$ and $\mathrm{Cu}_{3} \mathrm{Sn}$ were observed near the interface between the $\mathrm{Sn}$ films and $\mathrm{Cu}$ foils in the deposited Sn films (Fig. 7). With the gelatin additive, $\mathrm{Cu}_{6} \mathrm{Sn}_{5}$ formation and Kirkendall void formation occurred simultaneously with aging (as described in section 3.2 and our previous report ${ }^{7)}$ ). On the other hand, when heat treatment was used, both intermetallic compounds $\mathrm{Cu}_{6} \mathrm{Sn}_{5}$ and $\mathrm{Cu}_{3} \mathrm{Sn}$ were formed in the deposited $\mathrm{Sn}$ films without the formation of Kirkendall voids (Fig. 8 and 9). In addition, no change in the thickness of the intermetallic compounds by aging was observed in the deposited Sn films. These facts indicate that there is a difference in the formation process for the intermetallic compounds formed by aging and by heat treatment. Defects, such as grain boundaries, voids and dislocations, were not observed in the deposited Sn films and $\mathrm{Cu}$ foils with heat treatment (Fig. 8 and 9). These results indicate that the heat treatment induced recovery and recrystallization in the materials.

From the above results, the mechanisms of inhibition of intermetallic compound formation and whisker formation by the heat treatment are as follows. First, $\mathrm{Cu}$ atoms within the $\mathrm{Cu}$ foils diffuse into $\mathrm{Sn}$ and the intermetallic compounds are formed. In the part near the initial interface between the deposited $\mathrm{Sn}$ film and $\mathrm{Cu}$ foils, the intermetallic compound $\mathrm{Cu}_{3} \mathrm{Sn}$ was formed, since many $\mathrm{Cu}$ atoms can easily diffuse into $\mathrm{Sn}$. In the part far from the initial interface between the deposited $\mathrm{Sn}$ film and $\mathrm{Cu}$ foil, the intermetallic compound $\mathrm{Cu}_{6} \mathrm{Sn}_{5}$ was formed. In addition, recovery and recrystallization also occurred in the deposited $\mathrm{Sn}$ film and $\mathrm{Cu}$ foil during the intermetallic compound formation, as mentioned above. Finally, after the heat treatment, formation of intermetallic compounds with aging did not occur because the strain energy in the deposited $\mathrm{Sn}$ films was reduced by the recovery and recrystallization of the deposited $\mathrm{Sn}$ film and $\mathrm{Cu}$ foils. Thus, no whisker formation occurred in the deposited Sn film with aging.

The locational relationships and crystallographic coherency between the distribution of whisker formation sites and that of the intermetallic compound $\mathrm{Cu}_{6} \mathrm{Sn}_{5}$ in the deposited Sn films have been discussed in many studies. ${ }^{2-5)}$ However, in the present study, no locational relationship between the distribution of whiskers on the deposited $\mathrm{Sn}$ films and distribution of $\mathrm{Cu}_{6} \mathrm{Sn}_{5}$ in the deposited $\mathrm{Sn}$ films was observed. There was no crystallographic coherency between the whiskers and the intermetallic compounds, as confirmed in this study. For example, using the single crystal $\mathrm{Cu}$ plates (Fig. 3), while $\mathrm{Cu}_{6} \mathrm{Sn}_{5}$ had a uniform layer shaped structure, a large number of whiskers were formed. In addition, with heat treatment, while the structure of $\mathrm{Cu}_{6} \mathrm{Sn}_{5}$ was nodularshaped, whisker formation did not occur. These facts suggest that for whisker formation, the process of intermetallic compound formation is important, not just the amount of intermetallic compounds.

\section{Conclusions}

(1) In the case of using single crystal $\mathrm{Cu}$ plates, the number of whiskers formed on the deposited $\mathrm{Sn}$ films with the $\mathrm{Cu}$ single crystal plate (111) was the largest.

(2) The number of whiskers formed on the deposited Sn films, deposited using the hydrofluoboric acid bath, was the largest. 
(3) Using different types of $\mathrm{Cu}$ foils, the number of whiskers was changed by varying the grain size of the $\mathrm{Cu}$ foils.

(4) It is easy to form the intermetallic compound $\mathrm{Cu}_{6} \mathrm{Sn}_{5}$ when the deposited $\mathrm{Sn}$ films and $\mathrm{Cu}$ foils have a small grain size.

(5) With heat treatment, no whisker formation and no change in the thickness of the intermetallic compounds with aging were observed.

(6) The intermetallic compounds $\mathrm{Cu}_{6} \mathrm{Sn}_{5}$ and $\mathrm{Cu}_{3} \mathrm{Sn}$ were observed near the interface between the deposited $\mathrm{Sn}$ films and $\mathrm{Cu}$ foils.

The processes of intermetallic compound formation using substitutional deposition do not always coincide with that using electrodeposition. In particular, when using Sn substitutional deposition, the formation process of the interme- tallic compounds varies with the structures of the deposited Sn films and substrates.

\section{REFERENCES}

1) S. M. Arnold: Plating 53 (1996) 96-99.

2) K. S. Kim, C. H. Yu and J. M. Yang: Microelectr. Reli. 46 (2006) 10801086.

3) K. Tsuji: J. Surf. Finish. Soc. Japan 57 (2006) 451-458.

4) I. Boguslavsky and P. Bush: SUNY Buffalo, APEX conference, (March 31, 2003, Anaheim, California).

5) K. S. Kim, C. H. Yu and J. M. Yang: Thin Solid Films 504 (2006) 350354.

6) S. C. Britton: Trans. Inst. Met. Fin. 52 (1974) 95.

7) N. Okamoto, Y. Fujii, H. Kurihara and K. Kondo: Japan Inst. Metals 72 (2008) 413-419.

8) S. M. Foiles, M. I. Baskes and M. S. Daw: Phys. Rev. B 33 (1986) 7983. 